\title{
Rens Bod. A New History of the Humanities: The Search for Principles and Patterns from Antiquity to the Present
}

\section{Citation}

Blair, Ann. 2015. "Rens Bod. A New History of the Humanities: The Search for Principles and Patterns from Antiquity to the Present." The American Historical Review 120 (2) (April): 555-558. doi:10.1093/ahr/120.2.555.

\section{Published Version}

doi:10.1093/ahr/120.2.555

\section{Permanent link}

http://nrs.harvard.edu/urn-3:HUL.InstRepos:34334605

\section{Terms of Use}

This article was downloaded from Harvard University's DASH repository, and is made available under the terms and conditions applicable to Open Access Policy Articles, as set forth at http:// nrs.harvard.edu/urn-3:HUL.InstRepos:dash.current.terms-of-use\#OAP

\section{Share Your Story}

The Harvard community has made this article openly available.

Please share how this access benefits you. Submit a story.

\section{Accessibility}


manuscript of

Ann Blair, Joint featured book review of Rens Bod, A New History of the Humanities: The Search for Principles and Patterns from Antiquity to the Present (New York: Oxford University Press, 2013) and James Turner, Philology The Forgotten Origins of the Modern Humanities (Princeton: Princeton University Press, 2014), American Historical Review 120: 2 (2015), 555-558.

Rens Bod. A New History of the Humanities: The Search for Principles and Patterns from Antiquity to the Present. New York: Oxford University Press, 2013. Pp. xv, 384. $\$ 74.00$. James Turner. Philology: The Forgotten Origins of the Modern Humanities. Princeton, N.J.: Princeton University Press, 2014. Pp. xxiv, 550. \$35.00.

Rens Bod and James Turner each embarked a number of years ago on a dauntingly difficult project for which there was no precedent: to trace the history of the humanities across two millennia and many divergent disciplines. Imagine their surprise to discover one another only shortly before their books appeared in print at about the same time. These two remarkable studies illustrate the fragmentation of the humanities into separate disciplines and professional contexts, discernible in the significant differences in their treatments of the topic and in their separate but parallel geneses. At the same time, both books have much in common, from their commitment to a nuanced portrayal of a complex web of intellectual and institutional developments, to their call for a greater appreciation of the very durable achievements of humanistic inquiry. Taken singly or together, these volumes contribute a timely historical dimension to the current debates swirling around about the nature and value of the humanities. The disciplinary formations visible in universities today (which also vary by country) date from the relatively recent 
past (especially 1850-1900), but both authors show how they are rooted in much longer intellectual traditions.

Defining the humanities is a significant initial hurdle in writing their history. Turner and Bod have taken opposite tacks on this point. Turner's method is to start from one ancient term and field of interest — philology — and to trace its disciplinary descendants in three chronological segments: down to $1800,1800-1850$, and 1850-ca. 1910. In Hellenistic antiquity, philology encompassed four areas: language theory, rhetoric, textual criticism, and grammar. By the time of the Renaissance, philology had expanded to encompass all fields useful in interpreting antiquity, including history, chronology, poetry, and the antiquarian study of physical as well as textual remains. By the eighteenth century, the tools devised for the study of antiquity were applied to modern European, Near Eastern, and Amerindian languages and cultures, generating a wide range of fields that were professionalized in the late nineteenth century as archaeology, biblical philology, comparative linguistics, comparative religion, anthropology, literature and its many component parts (criticism, literary history, rhetoric), history, art history, and classics (which had become by 1900 just one humanistic discipline alongside many others). By the end of the nineteenth century, "the rubric 'humanities' came to label most of the new disciplines spawned by philology" (p. 234). Turner notes some discrepancies nonetheless: anthropology, theoretical linguistics, and biblical criticism are not usually labeled "humanities" even though they descended from philology, while music and philosophy, often classified as humanities, are not related to philology in Turner's view and do not feature in his account as a result. Music moved away from its original classification as a mathematical field of the quadrivium 
only in the eighteenth century (as Bod discusses). Turner points out that philosophy is not exclusively grouped with the humanities in Irish and British universities and argues that philosophy ended up in the humanities in American universities "from administrative convenience and accident of timing" (p. 381). During the late nineteenth century, American universities were shedding their explicitly religious ties, but parents, teachers, and students still felt the need for morally uplifting and character-forming instruction. They turned to the humanities especially to fill that need; courses in literature and art history, for example, often developed a spiritual angle in the late nineteenth century. Philosophy, with its tradition of moral reasoning, easily fit that profile and thus entered the humanities. In seeing philosophy and philology as opposites brought into the same disciplinary category by historical circumstance, Turner privileges a modern sense of the difference between these approaches and downplays the ways in which the two fields were also intertwined in the Renaissance humanist project of teaching morality through the philological study of philosophical texts.

By contrast with Turner's focus on the long career of one ancient discipline, Rens Bod starts from the current academic landscape to identify areas of study in the past and in non-European cultures, taking what he calls a "pragmatic stance": "the humanities are the disciplines that are taught and studied at humanities faculties" (p. 2). Of course Bod is well aware that disciplinary classifications vary today by national tradition and even within some countries from one institution to another. In practice Bod has selected fields that are in the humanities by broad current consensus and that suit his purposes. With a systematic approach Bod proceeds through four periods — ancient, medieval, early modern, and modern - to examine roughly eight different fields: linguistics (or the study 
of language), historiography (or the writing of history), philology and textual reconstruction, musicology, art theory, logic, rhetoric, and poetics (these last two are replaced by literary and theater studies and by media and cultural studies in the modern section). Bod, too, omits philosophy as a discipline; he considers that it subtends all the humanistic fields and he discusses philosophies of language, art, or history in the relevant sections. Bod explains the absence of theology in similar terms, as omnipresent in the premodern periods and therefore not in need of separate treatment. Thus religious and biblical studies and area studies more generally, which loom large in Turner's account, hardly appear in Bod's, in keeping perhaps also with their low visibility in humanities faculties today in Europe.

Bod and Turner have also defined their geographical scope very differently. After the first two chapters tracing the expansion of philology between antiquity and the seventeenth century, Turner focuses on the English-speaking Atlantic world: England, Ireland, Scotland, and North America. He argues that modern Anglo-American humanities were formed from "the heterogeneous stew of British philological erudition" in the later seventeenth and eighteenth centuries (p. 2). This tight focus on a geography interconnected by language, culture, and dense political and commercial interaction enables Turner to follow the formation of the intellectual and professional categories of the humanities through the twists and turns of the impact of individuals, institutions, and larger historical forces (e.g., imperial expansion, developments on the continent, reforms in higher education). More than once Turner notes the role of the "peripheral" contexts in embracing new developments. For example, the study of English as opposed to Latin rhetoric began in Scotland in the eighteenth century to improve the mastery of what was a 
foreign language to many Scots. Irish and American institutions similarly taught rhetoric from English authors in order to attune their graduates to the English elite. But Turner distinguishes this attention to literary texts as models to imitate from the teaching of literature as an object of analysis, which began in the nineteenth century (e.g., with George Ticknor's courses on French and Spanish literature at Harvard in 1819). Turner argues that in the late nineteenth century Oxford and Cambridge resisted the formation of alternatives to the classical curriculum and the introduction of the German model of classical philology with its emphasis on contextual analysis. On the one hand the students there were reluctant to enter new fields of study, which were less prestigious than the traditional classical tripos, and on the other hand, the Oxbridge dons were generalists devoted to their teaching habits and reluctant to embrace a new research program. University College London was instead the first British institution to welcome German philology. Meanwhile, Americans, who had no local access to the tools of scholarship, studied in Europe (especially after the Cunard Line began reliable steamship service in 1840) and brought back with them German models of scholarship and professionalization along with purchases of new and rare books. Turner also tracks the fitful reception of German higher criticism. First anthologized in English (with strategic omissions) in New York in 1829 and then the object of public indignation when widely disseminated in London in 1860, it was nonetheless adopted in the British academy by 1890 , but spread more slowly in the U.S., where biblical studies were taught principally in seminaries. Turner's expert focus enables him to offer a richly contextualized account of differentiated reactions and interactions. 
Bod, by contrast, casts a global net by complementing his main focus on Europe with sections on the different humanistic fields in China, India, and the Arab world, with occasional references to Africa. Although his treatments of non-Western developments become thinner for the later two periods, Bod has clearly mastered a vast swath of secondary and primary sources available on these areas in European languages. Bod draws special attention, for example, to the rule-based grammar of Sanskrit devised by Panini in India ca. 500 B.C.E., unrivaled until the modern period in its ability to describe a natural language by rules alone. He contrasts Panini with the eighth-century Persian Sibawayh whose description of Arabic was principally example-based, including an enumeration of peculiarities and exceptions to the grammatical concepts that he drew from the Greek Dionysius Thrax. In historiography Bod highlights the isnad, the Islamic notion of the chain of transmission that accompanied hadith or holy sayings in order to validate them. He also notes how the pattern of "rise, peak, and decline" (p. 21) appealed to historians in different contexts, including Sima Qian in ancient China and Herodotus in Greece, Ibn Khaldun in fourteenth-century Islam, and a number of early modern Europeans. Bod follows modern categories (of disciplines and themes) to identify promising areas for comparisons, which he then carries out with sensitivity to the terms and motives specific to each context. But he is less interested in the specifics of transmissions and interactions than in seeing what he calls meta-patterns that become visible by comparing humanistic disciplines on a grand scale. For example, Bod notes an overall pattern of cyclical shifts from descriptive humanities (in antiquity) to prescriptive (in the Middle Ages) back to description in the early modern period. Similarly he emphasizes the move from rule-based to example-based approaches (and sometimes back 
again) in linguistics and music, among other disciplines. Although Bod acknowledges the role of pattern-rejecting trends in the humanities, he is himself a pattern-seeker especially interested in pattern-seeking as a humanistic activity.

Strikingly, both authors have opted for a longue durée perspective, although neither makes any broad methodological claim for the merit of that over other time frames; this distinguishes their work from studies limited to a particular time and place like Jan Eckel's Geist der Zeit: deutsche Geisteswissenschaften seit 1870 (2008). Turner uses the 2,000-year span to emphasize the common ancestry of so many of the modern humanities. Through the processes of fragmentation, reconfiguration, and estrangement that shaped the humanistic disciplines over hundreds of years, Turner identifies the persistence of the defining features of philology: concerns for authentication, dating, and interpretation through the careful scrutiny and comparison of particulars studied in their cultural context. Comparative philological thinking created an awareness of cultural distance between the Renaissance and antiquity (first classical then biblical antiquity), then between Europe and the cultures of other continents (resulting in comparative linguistics and cultural anthropology), and was transferred from texts to images and artifacts with the formation of art history and archaeology. Turner highlights the presence of this single mental toolkit across so many disciplines through the careers of individuals who were involved in multiple fields, not only in the early modern period when we expect it, but also precisely during the period when modern disciplinary distinctions became institutionalized. For example, the Scottish biblical scholar William Robertson Smith drew the attention of philologists to comparative religion and anthropology; Charles Eliot Norton was a central figure in art history, archaeology, and Dante studies in 
the U.S.; and the German-born Friedrich Max Müller spent his career in Britain working in Sanskrit studies, linguistics, and comparative religion. James Turner is a distinguished intellectual historian well known to the history profession, especially in the United States. He has written landmark books on attitudes toward animal suffering in nineteenthcentury Britain and America, the rise of unbelief in the United States, the career of Charles Eliot Norton, and the history of American higher education. In those and this new book he is a consummate practitioner of the philological mindset that he studies.

By contrast, Rens Bod is a computational linguist by training. In his first book, Beyond Grammar: An Experience-Based Theory of Language (1998), Bod argued that accumulated language experiences analyzed electronically (notably with a "Data Oriented Parsing" method of his devising) describe a language better than any grammar. Bod has proceeded by applying a systematic set of questions (listed in Appendix A along with 15 follow-up questions) to uncover the methods and/or principles applied and the answers and patterns reached in each of the disciplines and contexts he considers. Bod uses the long time frame to highlight a continuous tradition of pattern-seeking in the humanities because "the quest for patterns . . . can be found in all disciplines, periods, and regions," not only in the study of nature but also in the study of "texts, languages, literature, music, art, theatre, and the past" (pp. 7, 9). Bod's method of celebrating the humanities is to emphasize features typically associated with success in the natural sciences. He argues that in most humanistic fields one can find a historical trend toward increased formalization of rules and patterns, and elements of progress measured by increased problem-solving capacity. Linguistics offers a splendid example of a field that considers itself progressive through the elucidation of rules, hence the appeal of Panini 
who accomplished the feat of a complete rule-based grammar in a time and place far remote from our own. Bod brings special expertise and enthusiasm to the history of his own field of training. He also emphasizes that the humanities have made crucial contributions to knowledge that deserve greater appreciation. For example, humanist philology was crucial in the overthrow of Aristotle, a step toward modernity that is usually solely credited to the "Scientific Revolution"; early modern historiography played a central role in breaking the constraints of the biblical time frame; and stemmatic philology is a "completed discipline" that offers a quasi-scientific method for the study of the transmission of texts. For Bod the big picture points to the absence of a radical dichotomy between the humanities and the sciences, except for a greater attention to exceptions in the former. Bod has written in the heroic mode, highlighting great achievements above all, but he does so responsibly. His accounts seem generally well founded within the constraints of a broad synthetic approach. Imbued with a strong sense of method, Bod is also careful to acknowledge that his history is selective, that the answers to some questions are uncertain, and that there is insufficient evidence to support some tempting conclusions.

Whether or not they were initially motivated by a sense of crisis in the humanities, both books will surely be read in that context. Bod's celebratory tone might help draw broader attention to the achievements of the humanities, but the nature of the book (though impressively well written by the author in English) and its price tag will probably ensure that it will mostly be read by those already persuaded of the merits of these fields. Bod's book is designed as an opening salvo in a grand project to develop the history of the humanities as a subfield on par with (and potentially in close alliance with) 
the history of science, with a view to building a history of knowledge-making more generally. He lays out the broadest possible contours of the field in order to invite further study, but judging from the collective projects he has organized so far, he does not enjoin others to take the same broad approach. Three conferences since 2008 have resulted in a series of volumes he co-edited with his colleagues Jaap Maat and Thijs Weststeijn in a series published by the University of Chicago: The Making of the Humanities, volume 1: Early Modern Europe (2010); volume 2: From Early Modern to Modern Disciplines (2012); and volume 3: The Making of the Modern Humanities (2014). Further conferences are planned for Baltimore 2016, Oxford 2017, and Beijing 2018. A new journal, History of the Humanities, will publish its first issue in 2016. The existing volumes organized by field within broad chronological categories bring together scholars from a wide range of disciplines all working on the intellectual and institutional history of various areas of knowledge. Bod is clearly committed to a pluralist interpretation of the humanities, though his own interests tend toward the pattern-seeking and the computational. In his wide embrace, the history of the humanities can certainly serve as a welcome venue to motivate new research projects and encourage collaborations. Bod's energetic initiatives are a fine example of the shifting categories of research, like those tracked by Turner in earlier periods, though it is hard to decide whether the lasting effect will be fragmentation (creating yet another subfield with professional journal and conferences) or consolidation (by giving those studying the history of humanistic fields an intellectual community they did not have before).

Turner does not pursue the history of the humanities far into the twentieth century. He stops before philology began its decline, the effects of which can be 
measured by the recent renaming of the American Philological Association (founded in 1869 ) as the Society for Classical Studies, a title constructed by analogy with area studies that emphasize the field's embrace of all those modern offshoots of philology (history, archaeology, art history, and literary interpretation) rather than the original core concerns of textual emendation, authentication, and dating. Turner notes that the humanistic disciplines as we know them were formed within the last 150 years at most. They are bound together by their shared philological ancestry even more than by the interdisciplinary initiatives that began in the early twentieth century, soon after professional specialization was established. Practitioners of the humanities today should therefore be open to further reconfigurations, including possible consolidations, of their disciplines in the future.

These books illustrate the value of a historical approach to the humanities in explaining both the long continuities and the contingent peculiarities behind the current web of academic disciplines. They also exemplify the distance that has formed through specialization within the humanities, notably between history and linguistics, which represent contrasting methodologies in the spectrum of disciplines descended from philology. The humanities will of course continue to evolve. Let us hope that their evolution is driven principally by the intellectual initiatives of their practitioners, not only by the introduction of new methods and sub-disciplines, but also by the revitalization of traditional ones, and combinations of old and new. The possibilities are many, as those involved in the edited volume World Philology (2015) illustrate by combining Bod's global perspective with Turner's disciplinary focus. 
AHR Reviews of Books: 202A

Ann Blair

Harvard University

Review Category: DOUBLE FEATURE (Methods/Theory) 